\title{
Bee venom inhibits the proliferation and migration of cervical-cancer cells in an HPV E6/E7-dependent manner
}

\author{
Da-Hyun Kim ${ }^{1,2}$, Hyun-Woo Lee ${ }^{1}$, Hyun-Woo Park ${ }^{3}$, Han-Woong Lee ${ }^{3}$ \& Kyung-Hee Chun ${ }^{1,2, *}$ \\ ${ }^{1}$ Department of Biochemistry \& Molecular Biology, Yonsei University College of Medicine, ${ }^{2}$ Brain Korea 21 PLUS Project for Medical \\ Science, Yonsei University College of Medicine, ${ }^{3}$ Department of Biochemistry, College of Life Science, Yonsei University, Seoul 03722, \\ Korea
}

Bee venom (BV), secreted from the venom gland of the honey bee, contains several biological active compounds. BV has been widely used as a traditional medicine for treating human disease, including cancer. In this study, we have shown the molecular mechanism underlying the therapeutic effect of BV on cancer. Treatment with BV reduced the proliferation of cervical-cancer cells in a dose- and time-dependent manner. Interestingly, the killing effect of BV was specific to HPVpositive cervical-cancer cell lines, such as Caski and HeLa cells, and not to HPV-negative cervical-cancer cells (C33A). BV reduced the expression of HPV E6 and E7 at RNA and protein levels, leading to an increase in the expression of p53 and Rb in Caski and HeLa cells. Further, BV decreased the levels of cell-cycle proteins, such as cyclin A and B, and increased the levels of cell-cycle inhibitors, such as p21 and p27. BV significantly induced apoptosis and inhibited wound healing and migration of cervical-cancer cells. It also upregulated the expression of pro-apoptotic BAX and downregulated the expression of anti-apoptotic Bcl-2 and Bcl-XL. Cleavage of caspase-3, caspase-9, and PARP were also induced by BV treatment, whereas the phosphorylation of mitogenic signalingrelated proteins, such as AKT, JNK, p38, and ERK, were downregulated. Our results indicate that BV has a therapeutic selectivity for HPV-positive malignant cells, so further clinical studies are needed to assess its clinical application. [BMB Reports 2020; 53(8): 419-424]

\section{INTRODUCTION}

Cervical cancer (CC) is one of the most common malignant cancers in women, with an estimated global mortality rate of

*Corresponding author. Tel: +82-2-2228-1699; Fax: +82-2-312-5041; E-mail: khchun@yuhs.ac

https://doi.org/10.5483/BMBRep.2020.53.8.031

Received 12 February 2020, Revised 17 February 2020, Accepted 17 February 2020

Keywords: Bee venom, Cervical cancer, Human papillomavirus
0.25 million deaths per year (1). Cervical cancer is caused by HPV infection, which is related to the metaplastic epithelium of the cervical transformation zones (2). Cervical cancer originates from abnormal cells in the lining of the uterine cervix. There are two primary types of cervical cancer, squamouscell cancer and adenocarcinoma. Squamous-cell cancer is the most common, and accounts for more than 70 of every 100 cases of cervical cancer. The incidence of adenocarcinoma has been reported to be less than that of squamous-cell cancer, but lately it has become more frequent (3). According to international guidelines, the standard treatment for CC consists of surgery in early-stage tumors, concomitant chemoradiation or neoadjuvant chemotherapy, followed by radical surgery in locally advanced disease, and chemotherapy alone for metastatic or recurrent disease (NCCN guidelines). Although earlystage and locally advanced cancer can be treated with potential curative intent (4), the removal of the cervix and uterus during surgery makes it impossible for the patient to become pregnant. Therefore, new therapeutic targets are needed to prevent problems with pregnancy and to improve the quality of life of women undergoing treatment for CC.

A possible way to inhibit the growth of cancer cells without any side effects is to use oriental medicine, such as bee venom (BV) (5). BV is secreted from the venom gland of the honey bee and contains several biologically active compounds (6). BV therapy is commonly used in Korean medicine as a treatment for various human diseases (7). Currently, BV targeted therapy has been developed for clinical treatment of conditions such as immune-related disorders. Recently several studies have helped explain the anti-cancer effect of BV on lung, liver, renal, prostate, breast and cervical-cancer cells (8). Melittin and phospholipase A2, known BV peptides, can serve as valuable, novel targets in the treatment of some types of cancer. However, further studies are required to investigate the therapeutic effect of BV on cervical cancer.

In this study, we demonstrated the therapeutic mechanism of BV in cervical-cancer cells, and more specifically, we identified the therapeutic effect of BV on HPV-positive and -negative cell lines. We detected induced apoptosis and reduced cell motility after BV treatment. Finally, we also investigated the expression of cell-cycle-regulated proteins and phosphoryl-

ISSN: 1976-670X (electronic edition)

Copyright (c) 2020 by the The Korean Society for Biochemistry and Molecular Biology

(c) This is an open-access article distributed under the terms of the Creative Commons Attribution Non-Commercial License (http://creativecommons.org/licenses/by-nc/4.0) which permits unrestricted non-commercial use, distribution, and reproduction in any medium, provided the original work is properly cited. 
ation of mitotic signaling-related proteins. Our results show that BV could serve as a potent cervical-cancer therapy agent.

\section{RESULTS}

Bee venom inhibits the proliferation and expression of HPV $\mathrm{E} 6$ and E7 and increases the expression of $\mathrm{p} 53$ and $\mathrm{Rb}$ proteins in HPV-positive cervical-cancer cells

To find out whether BV suppresses cell proliferation, we treated cervical-cancer cell lines Caski, C33A, and HeLa cells with various concentrations of BV $(0.625-10 \mu \mathrm{g} / \mathrm{ml})$. We observed a reduction in the proliferation rates of Caski and HeLa cells starting at $2.5 \mu \mathrm{g} / \mathrm{ml}$, although the same was not true for C33A cells (Fig. 1A). We then treated cells with $5 \mu \mathrm{g} / \mathrm{ml}$ of BV in a time-dependent manner. We found that over time, the proliferation rates of Caski and HeLa cells were reduced by half in response to the treatment; however, C33A cells did not respond to BV (Fig. 1B). Next, we treated the cells with $5 \mu \mathrm{g} /$ $\mathrm{ml}$ of BV and harvested them at various times $(0,12$, and 24 h). We showed that mRNA levels of HPV16 E6 and E7, and HPV18 E6 and E7 were decreased in Caski and HeLa cells (Fig. 1C). Since BV treatment of C33A cells did not result in any changes in cell proliferation, we did not quantify the mRNA expression of genes mentioned above. Moreover, we investigated the levels of their respective proteins after treating Caski and HeLa cells with various concentrations of BV. Protein expression of HPV16 E6 and HPV16 E7 was decreased upon increasing the concentrations of $\mathrm{BV}$, whereas the expression of p53 and Rb was increased (Fig. 1D). Overall these results strongly suggest that $\mathrm{BV}$ downregulates mRNA expression of E6 and E7, which leads to an increase in p53 and Rb expression, and thus inhibition of cervical-cancer cell proliferation.

\section{Bee venom significantly induces apoptosis in HPV-positive cervical-cancer cells}

To further investigate whether BV affects cell fate, we carried out PI staining analysis after treating Caski cells with BV. We found that, starting after $12 \mathrm{~h}$ treatment, the number of cells entering the sub-G1 phase had increased (Fig. 2A). We then measured the induction of apoptosis in BV-treated Caski cells using annexin $\mathrm{V}$ staining followed by FACS analysis, and observed an increase of annexin $\mathrm{V}$ positive cells in Caski cells. Less than $10 \%$ of BV-untreated cells exhibited background staining with annexin $\mathrm{V}$, whereas after BV treatment, more
A

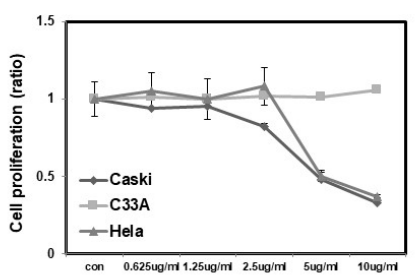

C

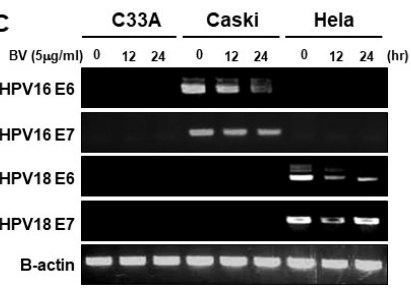

A

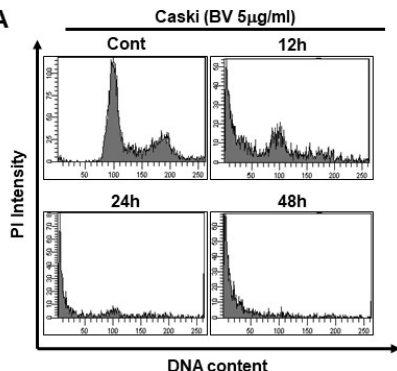

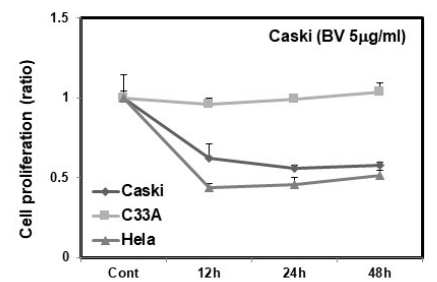

D

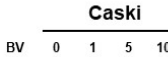

HPV16E6 HPV16E7

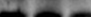

p53

p53
Rb

$\beta$-actin

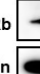

Hela

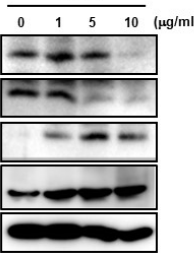

B

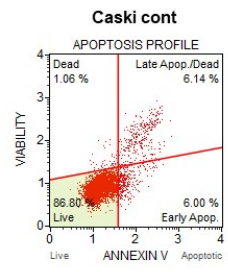

Caski (BV 5 $\mu \mathrm{g} / \mathrm{ml})$

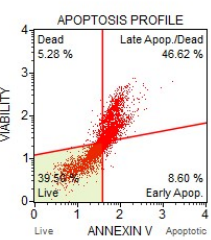

Fig. 1. Bee venom inhibits the proliferation and expression of HPV E6 and E7-positive cervical-cancer cells and increases the expression of p53 and $\mathrm{Rb}$ proteins. (A) WST cell proliferation assay showing dose-dependent inhibition of C33A, Caski and HeLa cells. C33A Caski, and HeLa cells were treated with $0,0.625,1.25,2.5,5$, and $10 \mu \mathrm{g} / \mathrm{ml}$ of BV for $24 \mathrm{~h}(\mathrm{~B})$. At $0,12,24$, and $48 \mathrm{~h}$ of treatment, we detected cell proliferation by MTT assay. (C) RT-PCRbased detection of time-dependent effects of $5 \mu \mathrm{g} / \mathrm{ml}$ of $\mathrm{BV}$ on the expression of HPV proteins, HPV16 E6, HPV 16 E7, HPV18 E6, and HPV E7 in C33A, Caski and HeLa cells treated for 0,12 , and $24 \mathrm{~h}$. (D) Protein levels of HPV16 E6, HPV16 E7, p53, and Rb in Caski and HeLa cells treated with 0 , 1,5 , and $10 \mu \mathrm{g} / \mathrm{ml}$ BV. $\beta$-actin was used as a loading control.

Fig. 2. Bee venom significantly induces apoptosis in HPV E6 and E7-positive cervical-cancer cells. (A) Representative data obtained from flow-cytometric analysis of cell-cycle markers after treatment of Caski cells with $5 \mu \mathrm{g} / \mathrm{ml}$ of BV for 0,12 , and $24 \mathrm{~h}$. We fixed cells using $1 \%$ PFA and stained DNA with $\mathrm{PI}$ as described in Materials and Methods. (B) Caski Cells were treated with BV $5 \mu \mathrm{g} / \mathrm{ml}$ for $24 \mathrm{~h}$ and harvested; then DNA was stained with propidium iodide before analysis using FACS. 
than $46 \%$ of the Caski cells were stained with annexin V, indicating induction of apoptosis and an increased population of dead cells (Fig. 2B). Overall, these data suggest that BV treatment induces apoptosis in HPV-positive cervical-cancer cells.

\section{Bee venom decreases cell motility of HPV-positive cervical-cancer cells}

We investigated whether BV-induced morphological changes could be linked to cell migration. In the background of BV treatment $(5 \mu \mathrm{g} / \mathrm{ml})$ in Caski cells and HeLa cells, we did wound healing (Fig. 3A) and migration assays (Fig. 3B). After BV treatment, we investigated cell motility at various times, including 0,12, 24, and $48 \mathrm{~h}$. We found that BV-treated Caski and HeLa cells exhibited less motility than did untreated cells (Fig. 3A and 3B). These results suggest that BV inhibits cell motility in HPV-positive cervical-cancer cells.

\section{Bee venom decreases the expression of cell-cycle-related proteins in HPV-positive cervical-cancer cells}

We showed that BV regulates cell-cycle proteins in HPV E6 and E7 oncogene-expressing cervical-cancer cells. Using Western blot analysis, we investigated the expression of cell-cycle proteins in BV-treated ( $5 \mu \mathrm{g} / \mathrm{ml}$ ) Caski and HeLa cells. BV treatment led to a significant increase in the protein levels of $\mathrm{Rb}$ and decreased the levels of cyclin A and cyclin B proteins (Fig. 4A).

To further investigate whether BV regulates the expression of tumor suppressors and cyclin-dependent kinase inhibitors, we checked the protein expression of p53, p21 $1^{\mathrm{Cip} 1}$, and p2 $7^{\mathrm{kip} 1}$ after BV treatment at 12 and $24 \mathrm{~h}$. As expected, levels of these proteins were increased in Caski and HeLa cells (Fig. 4B).

\section{Bee venom regulates the expression of apoptosis-related proteins}

We also investigated the effect of BV on the expression of apoptosis-related proteins. The levels of pro-apoptotic protein Bax increased after BV treatment, but those of the anti-apoptotic proteins BCl-2 and Bcl-X decreased (Fig. 4C). Consequent-
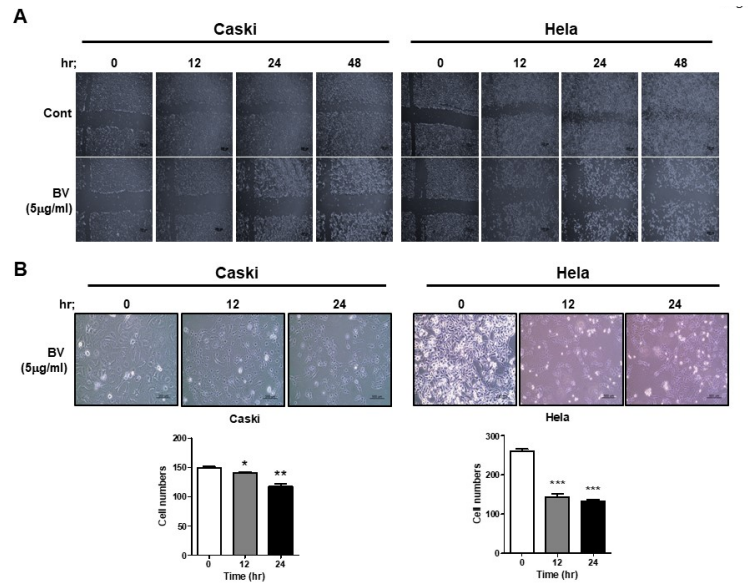

Fig. 3. Bee venom decreases the migration of HPV E6- and E7positive cervical-cancer cells. (A) We treated Caski and HeLa cells with BV (5 $\mu \mathrm{g} / \mathrm{ml}$ ) for $0,12,24$, and $48 \mathrm{~h}$. (B) Transwell migration assay. Caski and HeLa cells were treated with $5 \mu \mathrm{g} / \mathrm{ml}$ of BV for 0,12 , and $24 \mathrm{~h}$, and seeded into the upper chamber of a Transwell plate, before being allowed to vertically migrate towards the lower surface of the membrane. Migrating cells were stained with $0.1 \%$ crystal violet.
A

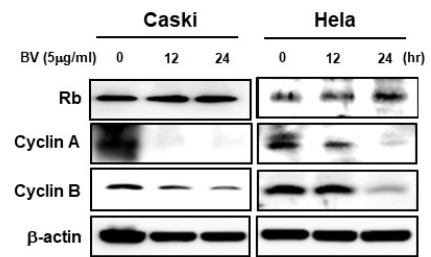

C

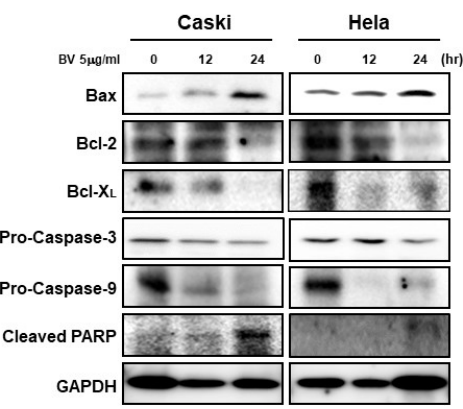

B

D

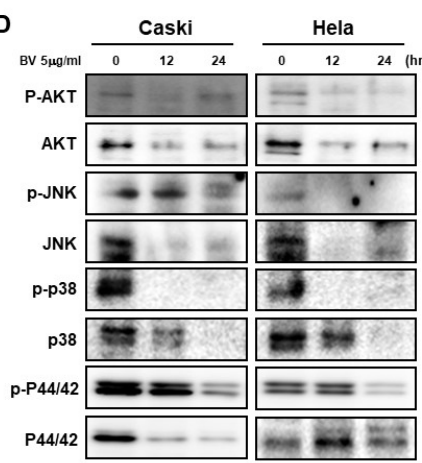

Fig. 4. Bee venom regulates the expression of cell-cycle inhibitors, apoptosisrelated proteins, and mitogenic signalingrelated proteins. (A) Western blot showing the time-dependent effects of BV on $\mathrm{Rb}$, cyclin $\mathrm{A}$, and cyclin $\mathrm{B}$ in Caski and HeLa cells treated for 0,12 , and $24 \mathrm{~h}$ with BV $(5 \mu \mathrm{g} / \mathrm{ml})$. (B) Expression of p53, p21, and p27 in Caski and HeLa cells treated with $5 \mu \mathrm{g} / \mathrm{ml}$ of BV was measured at 0,12 , and 24 $\mathrm{h}$ by Western blot. (C) Western blot of Caski and HeLa cells treated with $5 \mu \mathrm{g} / \mathrm{ml}$ of BV for 0,12 , and $24 \mathrm{~h}$. Immunoblot analysis of $\mathrm{Bax}, \mathrm{BCl}-2, \mathrm{BCl}$ $\mathrm{XL}$, pro-caspase-3, pro-caspase-9, and cleaved PARP. (D) We measured protein levels of $\mathrm{p}-\mathrm{AKT}, \mathrm{AKT}$, p-JNK, JNK, p-P38, P38, p-P44/42, and P44/42 by Western blot in Caski and HeLa cells treated with $5 \mu \mathrm{g} / \mathrm{ml}$ of BV for 0,12 , and 24 h. $\beta$-actin was used as a loading control. Data are presented as mean \pm SD $(n=3)$. Significant differences are indicated with an asterisk $\left({ }^{*} P<0.05\right.$, $* P<0.01), P$ values were calculated using the Student's t test. 
ly, pro-caspase-3, pro-caspase-9, and PARP were cleaved into their active forms (Fig. 4C).

Bee venom downregulates the mitogenic signaling pathways We also investigated whether mitogenic signaling pathways are regulated by $\mathrm{BV}$. We measured the expression of proteins related to the AKT, JNK, and mitogen-activated protein kinases (P38, P44/42) signaling pathways in HPV E6- and HPV E7positive cervical-cancer cells. Compared with BV-untreated cells, the phosphorylation of these proteins was decreased in a time-dependent manner in response to BV treatment (Fig. 4D).

\section{DISCUSSION}

HPV (Human Papilloma Virus) is known to be a prerequisite for the development of cervical cancer (9). Increased expression of $E 6$ and $E 7$ is responsible for the carcinogenic effects of HPV (10). Thus, mRNA expression of HPV E6 and E7 is correlated with the progression of cervical cancer. Accordingly, HPV E6 and E7 are used as markers for the diagnosis of cervical cancer (11). Given that the cervix is directly linked to female reproduction, it is crucial to find treatment options without adverse effects. However, surgery, chemotherapy, and radiation therapy are associated with infertility. For addressing this problem, research on alternative treatment approaches is actively under way. Biotoxin-based approaches can also serve as alternative treatments for cancer. One biotoxin in particular, bee venom, is widely known as a treatment for immunerelated diseases. Recent studies have shown that the main peptide component of BV, melittin, has an anti-cancer effect $(12,13)$. Melitin is a non-specific cytolytic peptide that can break down lipid bilayers and is toxic when injected (14). However, via an optimized nanoparticle-based approach, it exhibits anti-cancer effects on several cancer cells, including leukemia, liver cancer, lung cancer, and prostate cancer cells (15).

In this study, we confirmed that BV can effectively treat HPV E6 and E7-infected cervical-cancer cells. This could help us in specifically targeting cervical-cancer cells. We confirmed that BV downregulated the proliferation in HPV E6 and HPV E7-positive cervical-cancer cells; p53 and Rb, both tumor-suppressive proteins, are associated with HPV E6 and E7 proteins, suggesting a mechanism for viral proteins to induce cervical cancer (16). E6 protein promotes the degradation of the tumor suppressor p53 by forming a trimeric complex consisting of E6, p53, and a cellular ubiquitin ligase, E6-AP, thereby promoting the progression of cancer cells (17). A decrease in the levels of E6 proteins inhibits P53 function, thereby deregulating the cell cycle and stimulating the growth of cancer cells (18). Here, we observed an increased expression of p53 and $\mathrm{Rb}$ proteins in cervical-cancer cells after treatment with BV. In addition, several reports have shown that BV induces caspasedependent apoptosis (19). Our results revealed that the expression of $\mathrm{BCl} 2$ family proteins was greatly altered, a pheno- menon that seems to be a direct result of p53 activity.

In addition, we investigated whether BV affects mitogenic signaling pathways. The AKT signaling pathway plays an important role in various biological processes and in cancer progression and survival (20). Akt is activated through phosphorylation at the serine 473 residue (21). Activated Akt can phosphorylate downstream proteins, such as mTOR, BAD, and FOXO1, to regulate cancer-cell proliferation and viability. The JNK pathway is one of the pathways downstream to AKT and plays a crucial role in apoptosis and cancer-cell fate determination (22). Two upstream MAPKKs promote JNK activation (23). The MAPK signaling pathway plays a crucial role in tumor growth and apoptosis (24), and p38, a major MAP kinase is activated in cells in response to apoptosis and inflammatory cytokines. MAP/ERK kinase 1 and 2 phosphorylate p42 and p44 (ERK) MAP kinases. MAP3Ks trigger p28 MAPK activation, which promotes the activation of the JNK pathway (25), and p38 MAPK is an important factor in determining cancer-cell fate (26). We observed a significant decrease in AKT, JNK, p38, and p44/42 signals following BV treatment. Additionally, BV also inhibited the phosphorylation of these proteins in HPV E6 and E7 positive cervical-cancer cells.

Taken together, this study demonstrates that BV can play a role in inhibiting cervical-cancer tumorigenesis. Therefore, we posit that BV is an ideal approach for treating cervical cancer.

\section{MATERIALS AND METHODS}

\section{Cell line preparation and Bee venom treatment}

We obtained human cervical-cancer cell lines, C33A, Caski, and HeLa, from ATCC (Manassas, VA, USA). Cell lines were maintained in Dulbecco's modified Eagle's medium (DMEM) containing $10 \%$ fetal bovine serum (FBS) and $1 \%$ antibiotics (Invitrogen, Carlsbad, CA, USA), at $37^{\circ} \mathrm{C}$ in $5 \% \mathrm{CO}_{2}$ atmosphere, as previously described $(27,28)$. Cervical-cancer cells were seeded in 6-well plates and subsequently treated with BV $0-10 \mu \mathrm{g} / \mathrm{ml}$ for $24 \mathrm{~h}$. Bee Venom (Apis mellifera caucasia), Dried Bee Venom Powder was purchased by MyBiosouece (San Diego, USA).

\section{Analysis of cell proliferation}

We seeded cervical-cancer cells, C33A, Caski, and HeLa in 96-well culture plates $\left(3 \times 10^{3}\right.$ cells/well). After $24 \mathrm{~h}$, we treated C33A, Caski and HeLa cells with BV $(0-10 \mu \mathrm{g} / \mathrm{ml})$ for $24 \mathrm{~h}$. Following this treatment, highly sensitive water-soluble tetrazolium salt (WST) solution, purchased from Daeil (Seoul, Korea), was added to each well. After 1-3 h of incubation, we measured absorbance using an ELISA reader at a test wavelength of $450 \mathrm{~nm}(29,30)$

\section{Detection of cell cycle and apoptosis}

Caski cells were seeded in culture plates and treated with 5 $\mu \mathrm{g} / \mathrm{ml}$ of BV. Cells were harvested and then fixed with $70 \%$ $\mathrm{EtOH}(5 \mathrm{ml})$ overnight at $-20^{\circ} \mathrm{C}$. After fixation, cells were 
resuspended in propidium iodide (PI solution; RNaseA 50 $\mu \mathrm{g} / \mathrm{ml}, \mathrm{PI} 50 \mu \mathrm{g} / \mathrm{ml}$ in PBS) and transferred to FACS filter tubes. We evaluated cell-cycle distribution by PI staining using fluorescence-activated cell sorting (FACS). Caski cells were seeded in culture plates and treated with $5 \mu \mathrm{g} / \mathrm{ml}$ of BV. After $24 \mathrm{~h}$, cells were harvested and resuspended $\left(1 \times 10^{6}\right.$ cells $\left./ \mathrm{ml}\right)$ in Annexin V. Then, we transferred the solution (100 $\mu \mathrm{l})$ to a 1 -ml culture tube, and added $5 \mu \mathrm{l}$ of FITC Annexin $\mathrm{V}$ and 7-AAD to each sample. Cells were incubated for $15 \mathrm{~min}$ at RT in the dark. Then, we added $400 \mu \mathrm{l}$ of $1 \mathrm{x}$ Annexin Binding Buffer to each tube, after which the solution was transferred to FACS filter tubes. We measured apoptosis distribution by Annexin V staining using FACS (31).

\section{Wound-healing assay}

Caski and HeLa cells were seeded in 12-well plates and treated with $5 \mu \mathrm{g} / \mathrm{ml}$ of BV. A straight wound was created by scratching the cell surface with a 200- $\mu$ l pipette tip. Cells, maintained in serum-free DMEM, migrated to the wound area; these were then imaged using wide-field microscopy at 0,12 , 24 , and $48 \mathrm{~h}$ (32).

\section{Transwell migration assay}

We treated Caski and HeLa cells with $5 \mu \mathrm{g} / \mathrm{ml}$ of BV. After 24-h of treatment, cells $\left(2 \times 10^{4} /\right.$ well $)$ were isolated and added into the upper chamber of a Transwell plate (Corning, New York, USA). Chambers coated with $0.5 \mathrm{mg} / \mathrm{ml}$ collagen type I were purchased from BD bioscience (Seoul, Korea) for the migration assay. We added DMEM supplemented with $10 \% \mathrm{FBS}$ and $1 \%$ antibiotics to the lower chamber. Cells were then incubated for a further $24 \mathrm{~h}$, and those that migrated to the lower chamber were quantified after H\&E staining. For quantification, cells were counted in 5 randomly selected areas in each well using wide-field microscopy. Data were expressed as mean \pm SEM from three independent experiments.

\section{Western blot analysis}

Cells were lysed in RIPA buffer (Biosesang, Seoul, Korea) containing an Xpert protease-inhibitor cocktail (GenDEPOT, Barker, TX, USA) and a phosphatase inhibitor $\left(\mathrm{NaF}, \mathrm{Na}_{3} \mathrm{VO}_{4}\right)$. The cell lysate was centrifuged at 13,200 rpm for $20 \mathrm{~min}$ at $4^{\circ} \mathrm{C}$, after which the supernatant was collected. Proteins (20 $\mu \mathrm{g})$ were separated by SDS-PAGE and transferred onto PVDF membranes (Merck Millipore, Darmstadt, Germany). After transfer, membranes were blocked with 5\% skim milk (Becton Dickinson, Sparks, MD, USA) and incubated with primary antibody prepared in 5\% BSA (Bovagen Biologicals, Victoria, Australia) overnight at $4^{\circ} \mathrm{C}$. We then probed membranes with HRP-conjugated anti-mouse or anti-rabbit secondary antibody (Bethyl Laboratories, Montgomery, TX, USA) for $1 \mathrm{~h}$. Protein bands were detected by Clarity western ECL substrate (Bio-Rad, Hercules, CA, USA) using LAS 3000 (29). The following antibodies were used: anti- $\beta$-actin, anti-Rb, anti-Cyclin $A$, antiCyclin B, anti-P53, anti-P21, anti-P27, anti-BAX, anti-BCl 2, anti-
BCl-X $\mathrm{L}_{\mathrm{L}}$ anti-P-Akt, anti-Akt, anti-p-JNK, anti-JNK, anti-p-P38 anti-P38, anti-p-P44/42, and anti-P44/42 (Santa Cruz, Dallas, TX, USA). We also used anti-pro-caspase 3 and anti-pro-caspase9 antibodies that were purchased from Cell Signaling Technology (Beverly, MA, USA).

\section{Reverse Transcription-Polymerase Chain Reaction (RT-PCR)} We extracted total RNA from cells using Isol-RNA Lysis Reagent, which was purchased from 5prime (Gaithersburg, $M D, ~ U S A)$ and used according to the manufacturer's protocol (33). We synthesized cDNAs using $1 \mu \mathrm{g}$ of total RNA by using ReverTra Ace ${ }^{\circledR}$ qPCR RT Master Mix (TOYOBO, Tokyo, Japan). We did PCR using EX-taq DNA Polymerase, purchased from TaKaRa (Kyoto, Japan). The primer sequences were as follows: $\beta$-actin, 5'-AGCCTCGCCTTTGCCGA-3' (sense) and 5'-CTG GTGCCTGGGGCG-3' (anti-sense); HPV16 E6, 5'-GAA CAGCAATACAACACAAACCG-3' (sense) and 5'-CCACCGAC CCCTTATATTATG-3' (anti-sense) HPV16 E7, 5'-CAGCTCAGA GGAGGAGGATG-3' (sense) and 5'-CACAACCGAAGCGTAGA GTC-3' (anti-sense); HPV18 E6, 5'-ATCCAACACGGCGACCC TACAA-3' (sense) and 5'-CTGGATTCTATGTCACGAGCAAT-3' (anti-sense); HPV18 E7, 5'-ACCTTCTATGTCACGAGCAAT-3' (sense) and 5'-CGGACACACAAAGGACAGGGT-3' (anti-sense); P53, 5'-GGCCCACTTCACCGTACTAA-3' (sense) and 5'-GTGG TTTCAAGGCCAGATGT-3' (anti-sense); and Rb, 5'-TGTATCG GCTAGCCTATCTC-3' (sense) and 5'-AATTAACAAGGTGTGG TGG-3' (anti-sense).

\section{ACKNOWLEDGEMENTS}

This study was supported by the Bio \& Medical Technology Development Program of the National Research Foundation of Korea (NRF) funded by the Korean government, MSIP (NRF2015M3A9B6073835, NRF-2015M3A9B6073833), and the NRF grant awarded by the Korean government (NRF-2019R1A 2C2089237) to K.H.C.

\section{CONFLICTS OF INTEREST}

The authors have no conflicting interests.

\section{REFERENCES}

1. Bray F, Ferlay J, Soerjomataram I, Siegel RL, Torre LA and Jemal A (2018) Global cancer statistics 2018: GLOBOCAN estimates of incidence and mortality worldwide for 36 cancers in 185 countries. CA Cancer J Clin 68, 394-424

2. Hwang LY, Ma Y, Shiboski SC, Farhat S, Jonte J and Moscicki AB (2012) Active squamous metaplasia of the cervical epithelium is associated with subsequent acquisition of human papillomavirus 16 infection among healthy young women. J Infect Dis 206, 504-511

3. Marth C, Landoni F, Mahner S et al (2017) Cervical cancer: ESMO Clinical Practice Guidelines for diagnosis, treatment and follow-up. Ann Oncol 28, iv72-iv83 
4. Tomao F, Santangelo G, Musacchio L et al (2020) Targeting cervical cancer: Is there a role for poly (ADPribose) polymerase inhibition? J Cell Physiol 6, 5050-5058

5. Chaisakul J, Hodgson WC, Kuruppu S and Prasongsook N (2016) Effects of animal venoms and toxins on hallmarks of cancer. J Cancer 7, 1571-1578

6. Hossen MS, Shapla UM, Gan SH and Khalil MI (2017) Impact of bee venom enzymes on diseases and immune responses. Molecules 22, 25

7. Kim YS, Jun H, Chae Y et al (2005) The practice of Korean medicine: An overview of clinical trials in acupuncture. Evid Based Complement Alternat Med 2, 325-352

8. Kim YW, Chaturvedi PK, Chun SN, Lee YG and Ahn WS (2015) Honeybee venom possesses anticancer and antiviral effects by differential inhibition of HPV E6 and E7 expression on cervical cancer cell line. Oncol Rep 33, $1675-1682$

9. Walboomers JMM, Jacobs MV, Manos MM et al (1999) Human papillomavirus is a necessary cause of invasive cervical cancer worldwide. J Pathol 189, 12-19

10. Cyprian FS, Al-Farsi HF, Vranic S, Akhtar S and Al Moustafa AE (2018) Epstein-Barr virus and human papillomaviruses interactions and their roles in the initiation of epithelialmesenchymal transition and cancer progression. Front Oncol 8,111

11. Yao YL, Tian QF, Cheng B, Cheng YF, Ye J and Lu WG (2017) Human papillomavirus (HPV) E6/E7 mRNA detection in cervical exfoliated cells: a potential triage for HPV-positive women. J Zhejiang Univ Sci B 18, 256-262

12. Orsolic N (2012) Bee venom in cancer therapy. Cancer Metastasis Rev 31, 173-194

13. Rady I, Siddiqui IA, Rady M and Mukhtar H (2017) Melittin, a major peptide component of bee venom, and its conjugates in cancer therapy. Cancer Lett 402, 16-31

14. Hong JJ, Lu XM, Deng ZX, Xiao SF, Yuan B and Yang K (2019) How melittin inserts into cell membrane: conformational changes, Inter-Peptide Cooperation, and Disturbance on the Membrane. Molecules 24, 1775

15. Liu SJ, Yu M, He Y et al (2008) Melittin prevents liver cancer cell metastasis through inhibition of the Rac1dependent pathway. Hepatology 47, 1964-1973

16. Yim EK and Park JS (2005) The role of HPV E6 and E7 oncoproteins in HPV-associated cervical carcinogenesis. Cancer Res Treat 37, 319-324

17. Lipari F, McGibbon GA, Wardrop E and Cordingley MG (2001) Purification and biophysical characterization of a minimal functional domain and of an $\mathrm{N}$-terminal $\mathrm{Zn} 2+-$ binding fragment from the human papillomavirus type 16 E6 protein. Biochemistry 40, 1196-1204

18. Crook T, Tidy JA and Vousden KH (1991) Degradation of P53 can be targeted by Hpv E6 sequences distinct from those required for P53 binding and transactivation. Cell

\section{$67,547-556$}

19. Naseri $\mathrm{MH}$, Mahdavi $\mathrm{M}$, Davoodi J, Tackallou $\mathrm{SH}$ Goudarzvand M and Neishabouri SH (2015) Up regulation of $\mathrm{Bax}$ and down regulation of $\mathrm{Bcl} 2$ during 3-NC mediated apoptosis in human cancer cells. Cancer Cell Int 15,55

20. Cantley LC (2002) The phosphoinositide 3-kinase pathway. Science 296, 1655-1657

21. Sarbassov DD, Ali SM and Sabatini DM (2005) Growing roles for the mTOR pathway. Curr Opin Cell Biol 17, 596-603

22. Weston CR and Davis RJ (2007) The JNK signal transduction pathway. Curr Opin Cell Biol 19, 142-149

23. Tournier C, Dong C, Turner TK, Jones SN, Flavell RA and Davis RJ (2001) MKK7 is an essential component of the JNK signal transduction pathway activated by proinflammatory cytokines. Genes Dev 15, 1419-1426

24. Koul HK, Pal M and Koul S (2013) Role of p38 MAP kinase signal transduction in solid tumors. Genes Cancer 4, 342-359

25. Cuadrado A and Nebreda AR (2010) Mechanisms and functions of p38 MAPK signalling. Biochemical J 429, 403417

26. Koul HK and Khandrika L (2008) Signal transduction targets in prostate cancer. Curr Signal Transduct Ther 3, $112-128$

27. Lee HW, Jang KS, Choi HJ, Jo A, Cheong JH and Chun KH (2014) Celastrol inhibits gastric cancer growth by induction of apoptosis and autophagy. BMB Rep 47, 697-702

28. Kang HG, Kim WJ, Kang HG, Chun KH and Kim SJ (2019) Galectin-3 Interacts with C/EBPbeta and Upregulates Hyaluronan-Mediated Motility Receptor Expression in Gastric Cancer. Mol Cancer Res 18, 403-413

29. Cho Y, Kang HG, Kim SJ et al (2018) Post-translational modification of OCT4 in breast cancer tumorigenesis. Cell Death Differ 25, 1781-1795

30. Baek JH, Kim NJ, Song JK and Chun KH (2017) Kahweol inhibits lipid accumulation and induces Glucose-uptake through activation of AMP-activated protein kinase (AMPK). BMB Rep 50, 566-571

31. Kim SJ, Lee HW, Baek JH et al (2016) Activation of nuclear PTEN by inhibition of Notch signaling induces $\mathrm{G} 2 / \mathrm{M}$ cell cycle arrest in gastric cancer. Oncogene 35, 251-260

32. Kim SJ, Choi IJ, Cheong TC et al (2010) Galectin-3 increases gastric cancer cell motility by up-regulating fascin-1 expression. Gastroenterology 138, 1035-1045

33. Kim NJ, Baek JH, Lee J, Kim H, Song JK and Chun $\mathrm{KH}$ (2019) A PDE1 inhibitor reduces adipogenesis in mice via regulation of lipolysis and adipogenic cell signaling. Exp Mol Med 51, 5 